\title{
Effects of temperament on physiological, productive, and reproductive responses in Bos indicus beef cows ${ }^{1}$
}

\author{
R. F. Cooke, ${ }^{* 2}$ K. M. Schubach, $*$ R. S. Marques, $*$ R. F. G. Peres, $\dagger$ L. G. T. Silva, $* \dagger$ \\ R. S.Carvalho, $\uparrow$ R. S. Cipriano, $\$$ D. W. Bohnert, $*$ A. V. Pires, $§$ and J. L. M. Vasconcelos $\dagger$ \\ *Eastern Oregon Agricultural Research Center- Oregon State University, Burns, \\ OR 97720; †Faculdade de Medicina Veterinária e Zootecnia, Universidade Estadual Paulista, \\ Botucatu, SP, Brazil, 18618-970; † Unisalesiano Auxilium, Araçatuba, SP, Brazil, 16016-500; and \\ §Departamento de Zootecnia, ESALQ- Universidade de São Paulo, Piracicaba, SP, Brazil, 13418-900
}

\begin{abstract}
This experiment evaluated the effects of temperament on physiological, productive, and reproductive responses in Bos indicus beef cows. A total of 953 lactating, multiparous, non-pregnant Nelore cows (age $=99 \pm 2 \mathrm{mo}$; days post-partum $=51.4 \pm 0.3 \mathrm{~d}$; $\mathrm{BCS}=5.34 \pm 0.04 ; \mathrm{BW}=430 \pm 2 \mathrm{~kg}$ ) were allocated into 8 groups of approximately 120 cows each. Groups were assigned to an estrus synchronization + timedAI protocol at the beginning of the breeding season. Concurrently with AI, blood samples were collected, hair samples were clipped from the tail switch, and cow temperament was evaluated via chute score and exit velocity. Individual exit score was calculated within each group by dividing exit velocity into quintiles and assigning cows with a score from 1 to $5(1=$ slowest; $5=$ fastest cow). Temperament scores were calculated by averaging cow chute score and exit score, and used to define cow temperament ( $\leq 3=$ adequate, $n=726$; ADQ; $>3$ = excitable, $n=227$; EXC). Cows not pregnant to AI were assigned to a second timed-AI protocol $(n=184 \mathrm{ADQ}$ and $72 \mathrm{EXC})$ or exposed $(n=269 \mathrm{ADQ}$ and $90 \mathrm{EXC}$ ) to bulls for $60 \mathrm{~d}$. Pregnancy status was verified $30 \mathrm{~d}$ after each $\mathrm{AI}$ and $45 \mathrm{~d}$ after the breeding season via transrectal ultrasound. Cow age, BW, BCS,
\end{abstract}

and d post-partum at the beginning of the breeding season were similar $(P \geq 0.27)$ between ADQ and EXC cows. At first timed-AI, EXC had greater $(P<0.01)$ serum cortisol but similar $(P \geq 0.87)$ serum haptoglobin and hair cortisol concentrations compared with ADQ cows (49.1 vs. $39.1 \mathrm{ng} / \mathrm{mL}$ of serum cortisol, SEM = 1.0). Pregnancy rate to first timed-AI tended $(P=0.09)$ to be less in EXC vs. ADQ cows (41.0 vs. $47.3 \%$; SEM = 3.6), whereas no treatment differences were detected $(P \geq 0.23)$ for subsequent pregnancy outcomes. Calving rate was less $(P=0.04)$ in EXC vs. ADQ cows ( 68.3 vs. $74.8 \% ; \mathrm{SEM}=2.2$ ), which can be attributed to the greater $(P=0.05)$ pregnancy loss detected in EXC cows $(9.9$ vs. $5.9 \%$; SEM $=1.4)$. Weaning rate tended $(P=0.09)$ to be less, whereas calf weaning BW and age were less $(P \leq 0.05)$ in EXC vs. ADQ cows $(63.9$ vs. $69.4 \%, \mathrm{SEM}=2.4 ; 209$ vs. $212 \mathrm{~d}, \mathrm{SEM}=1 ; 204$ vs. $210 \mathrm{~kg}, \mathrm{SEM}=2)$. Hence, $\mathrm{kg}$ of calf weaned $/ \mathrm{cow}$ exposed to breeding was reduced $(P=0.04)$ in EXC vs. ADQ cows (130 vs. $146 \mathrm{~kg}, \mathrm{SEM}=5)$. In summary, $B$. indicus cows with excitable temperament had reduced reproductive performance and overall productivity compared to cohorts with adequate temperament when exposed to timed-AI + natural breeding.

Key words: beef cows, Bos indicus, production, reproduction, temperament

\footnotetext{
${ }^{1}$ Financial support for this research was provided by Fundação de Amparo à Pesquisa do Estado de São Paulo (Brazil; grants \#2014/14136-4 and \#2014/19485-7).

${ }^{2}$ Corresponding author: reinaldo.cooke@oregonstate.edu. Reinaldo Cooke also is affiliated as graduate professor to the
}

Programa de Pós-Graduação em Zootecnia/Faculdade de Medicina Veterinária e Zootecnia, UNESP- Univ. Estadual Paulista, Botucatu, SP, Brazil, 18618-970.

Received October 5, 2016.

Accepted October 31, 2016. 


\section{INTRODUCTION}

Temperament is defined as the fear-related behavioral responses of cattle when exposed to human handling (Fordyce et al., 1988), whereas excitable temperament has been shown to impair reproductive performance in Bos taurus-influenced cows (Cooke et al., 2009; Cooke et al., 2012). This outcome was associated with increased circulating cortisol concentrations in cows with excitable temperament (Cooke, 2014), given that cortisol impairs fertility and pregnancy maintenance (Dobson et al., 2001). Moreover, B. taurus cows with excitable temperament had reduced calving rate, weaning rate, and $\mathrm{kg}$ of calf weaned/cow exposed to breeding compared to cows with adequate temperament, indicating that excitable temperament impacts overall production efficiency in cow-calf systems (Cooke et al., 2012).

Excitable temperament is observed more frequently in B. indicus compared with B. taurus-influenced cattle (Hearnshaw and Morris, 1984; Fordyce et al., 1988). Given that $B$. indicus breeds are predominant in tropical and subtropical regions of the planet, our research group also investigated and reported reduced pregnancy rates to fixed-time AI in Nelore cows with excitable temperament (Cooke et al., 2011). However, research is still required to further comprehend the impacts of temperament on productive and reproductive outcomes in $B$. indicus cowherds. These include reproductive and overall productivity in females following a typical AI + bull breeding season (Vasconcelos et al., 2014), calving season, and at offspring weaning. In addition, physiological links between temperament and reproductive function need to be evaluated in $B$. indicus cows (Cooke et al., 2011) including cortisol concentrations in hair from the tail switch, which has been recently identified as biomarker of chronic stress in cattle (Moya et al., 2015). Therefore, this experiment investigated the impacts of temperament on physiological, productive, and reproductive parameters of $B$. indicus cows.

\section{MATERIALS AND METHODS}

This experiment was conducted from January 2015 to August 2016 in a commercial cow-calf operation located in Nova Xavantina, MT, Brazil. The animals utilized herein were cared for in accordance with the practices outlined in the Guide for the Care and Use of Agricultural Animals in Agricultural Research and Teaching (FASS, 2010).

\section{Animals and reproductive management}

A total of 953 lactating, multiparous, non-pregnant Nelore cows (age $=99 \pm 2 \mathrm{mo}$, d post-partum $=51.4 \pm 0.3$ $\mathrm{d} ; \mathrm{BW}=430 \pm 2 \mathrm{~kg}$, and $\mathrm{BCS}=5.34 \pm 0.04$ according to Wagner et al., 1988) were assigned to the experiment. Cows were allocated into 8 groups of approximately 120 cows each (range $=114$ to 123 cows/group) according to the general management scheme of the operation. Groups were maintained in individual Brachiaria brizantha pastures with ad libitum access to water and a commercial mineral-vitamin mix (DSM Produtos Nutricionais Brasil, São Paulo, SP, Brazil).

Reproductive management also followed the management scheme of the operation, and was independent of cattle temperament and the objectives of this experiment. All groups were assigned to an estrus synchronization + fixed-time AI protocol at the beginning of the 2015 breeding season (Meneghetti et al., 2009). Within each group, cows were inseminated by 1 of 2 technicians with semen from 2 different Angus sires. Pregnancy status to first timed-AI was verified by detecting a viable conceptus with transrectal ultrasonography $(5.0-\mathrm{MHz}$ transducer; 500V, Aloka, Wallingford, CT) $30 \mathrm{~d}$ after AI. Cows diagnosed as non-pregnant were either exposed immediately to mature Nelore bulls (1:20 bull to cow ratio) for $60 \mathrm{~d}$ ( $n=242$ cows from 3 groups), assigned to a second synchronization + fixed-time AI protocol (Meneghetti et al., 2009; $n=256$ cows from 5 groups), or culled ( $n=19)$. Cows assigned to the second timed-AI were inseminated by 1 of 2 technicians with semen from 2 different Angus sires within each group, and pregnancy status was verified $30 \mathrm{~d}$ after AI as previously described. Cows diagnosed as non-pregnant to second timed-AI from 4 of the groups $(n=117)$ were exposed to mature Nelore bulls (1:20 bull to cow ratio) for $60 \mathrm{~d}$, whereas cows diagnosed as nonpregnant to second timed-AI from 1 of the groups $(n=32)$ were not exposed to bull breeding and culled from the operation. All bulls utilized in this experiment were submitted to and approved by a breeding soundness evaluation (Chenoweth and Ball, 1980) before the breeding season.

Final pregnancy status was verified by detecting a viable fetus with transrectal ultrasonography $(5.0-\mathrm{MHz}$ transducer; 500V, Aloka, Wallingford, CT) $45 \mathrm{~d}$ after the end of breeding season. Pregnancy loss was calculated based on pregnancy diagnosis after the breeding season and actual calving rates. Calving was completed within a 15-wk interval for all groups. Calf birth date was recorded and used for calving distribution analysis, which was based on a 15-wk calving season within each group. Calf BW was determined at weaning.

\section{Sampling and temperament evaluation}

Cow BW and BCS (Wagner et al., 1988) were recorded at the beginning of the breeding season, when cows were processed for the first time during the estrus synchronization protocol (Meneghetti et al., 2009). Blood samples were collected and hair samples were clipped 
from the tail switch (Burnett et al., 2014) when cows were restrained for the first timed-AI. Blood samples were collected from either the coccygeal vein or artery into commercial blood collection tubes (Vacutainer, 10 mL; Becton Dickinson, Franklin Lakes, NJ). Hair was collected using scissors as close to the skin as possible, and the hair material closest to the skin $(2.5 \mathrm{~cm}$ of length, $300 \mathrm{mg}$ of weight) was stored at $-20^{\circ} \mathrm{C}$ until processed for cortisol extraction.

Individual cow temperament was assessed by chute score and exit velocity as previously described by Cooke (2014), concurrently with the first timed-AI. Chute score was assessed by a single technician based on a 5-point scale where: $1=$ calm with no movement, $2=$ restless movements, 3 = frequent movement with vocalization, $4=$ constant movement, vocalization, shaking of the chute, and $5=$ violent and continuous struggling. Exit velocity was assessed immediately by determining the speed of the cow exiting the squeeze chute by measuring rate of travel over a 1.9-m distance with an infrared sensor (FarmTek Inc., North Wylie, TX). Cows were divided within group into quintiles according to their exit velocity, and assigned a score from 1 to 5 (exit score; $1=$ cows within the slowest quintile; $5=$ cows within the fastest quintile). Individual temperament scores were calculated by averaging cow chute score and exit score. Cows were classified according to the final temperament score (temperament type) as adequate temperament (ADQ; temperament score $\leq 3$ ) or excitable temperament $(\mathbf{E X C}$; temperament score $>3$ ).

\section{Laboratorial analyses}

Blood samples were placed immediately on ice after collection, allowed to clot for $24 \mathrm{~h}$ at $4^{\circ} \mathrm{C}$, centrifuged at $1000 \times g$ at room temperature for $15 \mathrm{~min}$ for serum collection, and stored at $-20^{\circ} \mathrm{C}$. Serum cortisol concentrations were determined using a chemiluminescent enzyme immunoassay (Immulite 1000; Siemens Medical Solutions Diagnostics, Los Angeles, CA). Serum haptoglobin concentrations were determined according to the colorimetric procedure described by Cooke and Arthington (2013). The intra- and inter-assay CV were, respectively, 3.0 and $2.1 \%$ for serum cortisol, and 2.2 and $5.7 \%$ for serum haptoglobin.

Cortisol was extracted from hair samples based on the procedures described by Moya et al. (2013). Briefly, hair samples were cleaned with warm water $\left(37^{\circ} \mathrm{C}\right)$ for $30 \mathrm{~min}$, and dried at room temperature for $24 \mathrm{~h}$. Hair samples were then washed twice with isopropanol, dried at room temperature for $120 \mathrm{~h}$, and ground in a $10-\mathrm{mL}$ stainless steel milling cup with a $12-\mathrm{mm}$ stainless steel ball (Retsch Mixer Mill MM400 ball mill; Retsch, Hannover, Germany) for $5 \mathrm{~min}$ at a frequency of
30 repetitions/s. Twenty $\mathrm{mg}$ of ground hair and $1 \mathrm{~mL}$ of methanol were combined into a $7-\mathrm{mL}$ glass scintillation vial, sonicated for $30 \mathrm{~min}$, and incubated for $18 \mathrm{~h}$ at $50^{\circ} \mathrm{C}$ and $100 \mathrm{rpm}$ for steroid extraction. Upon incubation, 0.8 $\mathrm{mL}$ of methanol was transferred to a $2-\mathrm{mL}$ microcentrifuge tube and evaporated at $45^{\circ} \mathrm{C}$. Samples were reconstituted in $100 \mu \mathrm{L}$ of the PBS supplied with a salivary cortisol ELISA kit (Salimetrics Expanded Range, High Sensitivity 1-E3002, State College, PA), and stored at $-80^{\circ} \mathrm{C}$. Samples were analyzed for cortisol concentrations using the aforementioned ELISA kit, whereas intra- and inter-assay CV were, respectively, 1.9 and 3.3\%.

\section{Statistical Analyses}

All data were analyzed using cow as experimental unit and Satterthwaite approximation to determine the denominator df for the tests of fixed effects. All model statements contained the effect of cow temperament type (ADQ or EXC), whereas model for calving distribution also included the effects of wk and the temperament type $\times$ wk interaction. Quantitative data such as cow BCS, serum and hair measurements, and calf weaning BW were analyzed with the MIXED procedure of SAS (SAS Inst., Inc., Cary, NC) with cow(temperament type $\times$ group) as random variable. Binary data such as pregnancy rates, calving rate and distribution, and pregnancy loss were analyzed with the GLIMMIX procedure of SAS (SAS Inst., Inc) with cow(temperament type $\times$ group) as random variable, in addition to sire(group) and AI technician(group) as random variables for pregnancy rates to first and second timed-AI. The probability of cows to become pregnant to first timed-AI was evaluated according to hair cortisol, serum cortisol, and serum haptoglobin concentrations. The GLM procedure of SAS was initially used to determine if each individual measurement influenced pregnancy maintenance linearly, quadratically, or cubically. The LOGISTIC procedure was used to generate the regression model, determine the intercept and slope(s) values according to maximum likelihood estimates from each significant continuous order effect, and the probability of pregnancy was determined according to the following equation: Probability $=\left(\mathrm{e}^{\text {lo- }}\right.$ gistic equation $) /\left(1+\mathrm{e}^{\text {logistic equation }}\right)$. Logistic curves were constructed according to the minimum and maximum values detected for each variable. For all analyses, significance was set at $P \leq 0.05$ and tendencies were determined if $P>0.05$ and $P \leq 0.10$.

\section{RESULTS AND DISCUSSION}

Based on the temperament evaluation criteria adopted herein, all groups had similar $(P \geq 0.64)$ mean temperament score $(2.48 \pm 0.08)$ and proportion of EXC 
Table 1. Cow and physiological variables in Nelore (Bos indicus) beef cows according to temperament

\begin{tabular}{|c|c|c|c|c|}
\hline \multirow[b]{2}{*}{ Item } & \multicolumn{2}{|c|}{ Temperament type $^{1}$} & \multirow[b]{2}{*}{ SEM } & \multirow[b]{2}{*}{$P=$} \\
\hline & Adequate $(n=726)$ & Excitable $(n=227)$ & & \\
\hline \multicolumn{5}{|l|}{ Cow variables $^{2}$} \\
\hline Age, mo & 100 & 96 & 2.56 & 0.27 \\
\hline Days post-partum, $\mathrm{d}$ & 51.4 & 51.3 & 0.43 & 0.95 \\
\hline $\mathrm{BW}, \mathrm{kg}$ & 431 & 427 & 3 & 0.28 \\
\hline BCS & 5.34 & 5.33 & 0.05 & 0.91 \\
\hline \multicolumn{5}{|l|}{ Physiological variables ${ }^{3}$} \\
\hline Serum cortisol, $\mathrm{ng} / \mathrm{mL}$ & 39.1 & 49.1 & 1.0 & $<0.01$ \\
\hline Serum haptoglobin, $\mu \mathrm{g} / \mathrm{mL}$ & 276 & 280 & 21 & 0.91 \\
\hline Hair cortisol, $\mathrm{pg} / \mathrm{mg}$ of hair & 4.31 & 4.23 & 0.23 & 0.81 \\
\hline
\end{tabular}

${ }^{1}$ Calculated based on cow temperament score (adequate temperament, temperament score $\leq 3$; excitable temperament, temperament score $>3$ ) assessed at the first timed-AI of the breeding season (Meneghetti et al., 2009). Temperament score was calculated by averaging cow chute score and exit score. Exit score was calculated by dividing exit velocity results into quintiles and assigning cows with a score from 1 to 5 (exit score: $1=$ slowest cows; $5=$ fastest cow).

${ }^{2}$ Values collected (BCS according to Wagner et al., 1988) at the beginning of the breeding season (Meneghetti et al., 2009).

${ }^{3}$ Blood samples and hair samples from the tail switch were collected concurrently with the first timed-AI of the breeding season (Meneghetti et al., 2009).

cows (726 ADQ cows and 227 EXC cows; $23.8 \% \pm 3.9$ of EXC cows/total cows). Matsunaga et al. (2002) estimated that the incidence of excitable Nelore cattle in Brazilian beef operations is at $10 \%$, which differs from the results reported herein. This discrepancy can be attributed to several factors, including number of cattle evaluated, differences in cattle population and production systems, as well as temperament evaluation criteria (Cooke et al., 2011). Nevertheless, the goal of this experiment was to investigate the impacts of temperament on reproductive performance and overall productivity in $B$. indicus beef females, and not to determine the incidence of excitable females in $B$. indicus cowherds. The methods used herein to evaluate temperament cattle were similar to our previous research efforts with $B$. taurus and B. indicus cows (Cooke et al., 2011; Cooke et al., 2012; Francisco et al., 2015), and have the purpose of classifying cattle according to temperament characteristics by using techniques that can be feasibly completed during routine cattle processing (Cooke, 2014).

No temperament type effects were $(P \geq 0.27)$ detected for cow age and d postpartum at the beginning of the breeding season (Table 1); hence, any physiological, productive and reproductive differences between ADQ and EXC cows should not be related to these variables. In addition, $d$ postpartum values indicate that cows were within the recommended voluntary waiting period for B. indicus cattle (Vasconcelos et al., 2014). Cow BCS and BW (Table 1) were also similar $(P \geq 0.28)$ between EXC and ADQ cows, which suggests that any effects of temperament type on productive and reproductive outcomes were also independent of cow nutritional status at the beginning of the breeding season (Cooke et al., 2009; Cooke et al., 2011; Cooke et al., 2012).

Serum cortisol concentrations were greater $(P<0.01)$ in EXC vs. ADQ cows at the first timed-AI (Table 1).
These results concur with previous findings from our (Cooke et al., 2009; Cooke et al., 2012) and other research groups (Stahringer et al., 1990; Fell et al., 1999; Curley et al., 2006), demonstrating that cattle with excitable temperament have heightened adrenocortical stress reaction during handling compared with calmer cohorts (Burdick et al., 2011; Cooke, 2014). Elevated cortisol has also been positively associated with circulating haptoglobin concentrations in cattle (Cooke et al., 2012), which is a key component of the bovine acute-phase protein response (Carroll and Forsberg, 2007) known to impact cattle productive and reproductive efficiency (Cooke et al., 2009; Araujo et al., 2010). However, no temperament type effects were detected $(P=0.91)$ for serum haptoglobin at the first timed-AI (Table 1), indicating that the increase in adrenocortical activity of EXC cows during handling for timed-AI was not sufficient to concomitantly impact the acute-phase protein reaction. Yet, serum haptoglobin concentrations peak 24 to $72 \mathrm{~h}$ after an acute stressor in cattle (Arthington et al., 2008; Cooke and Bohnert, 2011), and serum haptoglobin and cortisol concentrations were analyzed at timed-AI. It is important to note that cows were also handled for estrus synchronization 2, 4, and $11 \mathrm{~d}$ prior to timed-AI (Meneghetti et al., 2009). Therefore, similar serum haptoglobin concentration between temperament types at timed-AI also indicates that heightened adrenocortical stress reaction to handling in EXC vs. ADQ cows (Burdick et al., 2011; Cooke, 2014) during estrus synchronization was not sufficient to alter acute-phase protein parameters.

Hair cortisol concentrations were similar $(P=0.81)$ between EXC and ADQ cows (Table 1). Cortisol concentration in hair from the tail switch has been recently identified as biomarker of chronic stress in cattle (Burnett et al., 2014; Marti et al., 2015; Moya et al., 2015), given that cortisol is gradually accumulated in the emerg- 
Table 2. Reproductive performance of Nelore (Bos indicus) beef cows according to temperament

\begin{tabular}{|c|c|c|c|c|}
\hline \multirow[b]{2}{*}{ Item } & \multicolumn{2}{|c|}{ Temperament type ${ }^{1}$} & \multirow[b]{2}{*}{ SEM } & \multirow[b]{2}{*}{$P=$} \\
\hline & Adequate & Excitable & & \\
\hline \multicolumn{5}{|l|}{ Pregnancy rates, $2,3 \%$} \\
\hline First timed-AI & $47.3(341 / 726)$ & $41.0(95 / 227)$ & 3.6 & 0.09 \\
\hline Second timed-AI & $43.1(79 / 184)$ & $39.2(28 / 72)$ & 5.1 & 0.56 \\
\hline Natural breeding & $58.4(157 / 269)$ & $54.4(49 / 90)$ & 4.1 & 0.52 \\
\hline Final (AI + natural) & $79.5(577 / 726)$ & $75.8(172 / 227)$ & 2.1 & 0.23 \\
\hline Calving rate, ${ }^{4 \%} \%$ & $74.8(543 / 726)$ & $68.3(155 / 227)$ & 2.2 & 0.04 \\
\hline Pregnancy loss, ${ }^{5 \%}$ & $5.9(34 / 577)$ & $9.9(17 / 172)$ & 1.4 & 0.05 \\
\hline
\end{tabular}

${ }^{1}$ Calculated based on cow temperament score (adequate temperament, temperament score $\leq 3$; excitable temperament, temperament score $>3$ ) assessed at the first timed-AI of the breeding season (Meneghetti et al., 2009). Temperament score was calculated by averaging cow chute score and exit score. Exit score was calculated by dividing exit velocity results into quintiles and assigning cows with a score from 1 to 5 (exit score: $1=$ slowest cows; $5=$ fastest cow).

${ }^{2}$ Cows were assigned to an estrus synchronization + timed-AI protocol at the beginning of the breeding season (Meneghetti et al., 2009). Cows not pregnant to first timed-AI were assigned to a second timed-AI protocol and/or exposed to natural breeding for $50 \mathrm{~d}$. Pregnancy status was verified $30 \mathrm{~d}$ after each $\mathrm{AI}$ and $45 \mathrm{~d}$ after the breeding season via transrectal ultrasonography (5.0-MHz transducer; 500V, Aloka, Wallingford, CT). Values within parenthesis represent pregnant cows divided by cows exposed to AI and/or natural breeding.

${ }^{3}$ Based on the management scheme of the operation, cows not pregnant to first timed-AI $(\mathrm{ADQ}=385, \mathrm{EXC}=132)$ were immediately culled from the operation $(\mathrm{ADQ}=14, \mathrm{EXC}=5)$ or assigned to natural breeding only $(\mathrm{ADQ}=187, \mathrm{EXC}=55)$, second timed- $\mathrm{AI}$ only $(\mathrm{ADQ}=102, \mathrm{EXC}=37)$, or second timed-AI followed by natural breeding $(\mathrm{ADQ}=82, \mathrm{EXC}=35)$.

${ }^{4}$ Values within parenthesis represent cows that gave birth to a calf divided by cows exposed to AI and/or natural breeding.

${ }^{5}$ Pregnancy loss was calculated based on pregnancy diagnosis $45 \mathrm{~d}$ after the breeding season and calving rates. Values within parenthesis represent cows that lost pregnancy divided by cows diagnosed as pregnant on the end of the breeding season.

ing tail hair and its concentration represents long-term adrenocortical activity (Moya et al., 2013). Research by González-de-la-Vara et al. (2011) suggested that hair cortisol concentrations represent adrenocortical activity during the 14-d interval prior to hair collection, although these authors clipped hair from the coastal region of dairy cattle. Moreover, measuring cortisol in hair from the tail switch eliminates the effects that handling cattle exert on circulating cortisol concentrations (Moya et al., 2013, Moya et al., 2015), given that hair cortisol concentrations are not instantly impacted by the stress of handling (Burnett et al., 2014). In the present experiment, cows were handled 4 times during the 11-d estrus synchronization + protocol (Meneghetti et al., 2009). Hence, the lack of treatment effects on hair cortisol concentrations suggest that increased adrenocortical stress reaction of EXC cows during handling for estrus synchronization + timed-AI was not sufficient to chronically impact adrenocortical activity. Nevertheless, research is still required to explore the associations among temperament, handling frequency, and hair cortisol concentrations in beef cattle.

Pregnancy rate to first timed-AI tended $(P=0.09)$ to be less in EXC vs. ADQ cows (Table 2), corroborating with previous research with $B$. indicus females (Cooke et al., 2011; Rueda et al., 2015). These outcomes can be attributed, at least partially, to the greater adrenocortical stress responses and serum cortisol concentrations (Table 1) in EXC cows stimulated by handling for estrus synchronization and AI. Cortisol directly impairs the physiological mechanisms required for fertility in beef cows (Dobson et al., 2001). These include disrupted synthesis and release of gonadotropins ( $\mathrm{Li}$ and Wagner,
1983; Dobson et al., 2000), reduced sensitivity of the brain to estrogen (Hein and Allrich, 1992), and impaired progesterone production by the corpus luteum (Wagner et al., 1972; da Rosa and Wagner, 1981). Supporting this rationale, the probability of cows becoming pregnant to first timed-AI was decreased linearly $(P<0.01)$ as serum cortisol concentrations increased (Fig. 1). A similar out-
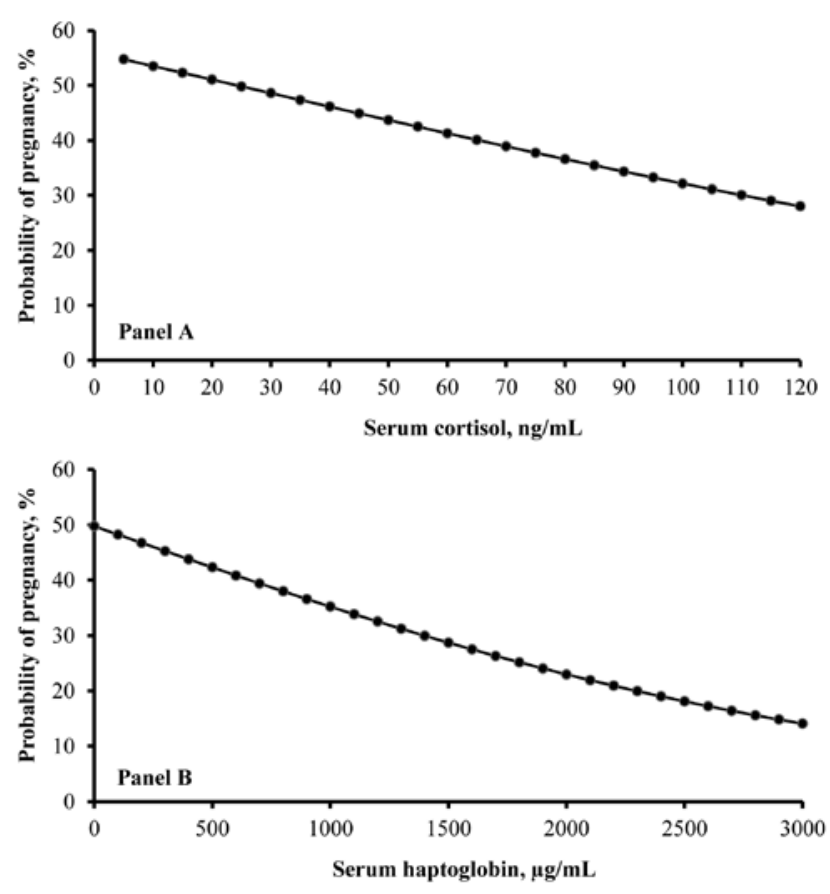

Figure 1. Probability of pregnancy to fixed-time AI in Nelore (Bos indicus) beef cows according serum cortisol (panel A) and haptoglobin (panel B) concentrations at the time of AI. Pregnancy status was verified $30 \mathrm{~d}$ after AI via transrectal ultrasonography $(5.0-\mathrm{MHz}$ transducer; $500 \mathrm{~V}$, Aloka, Wallingford, CT). A linear effect was detected $(P<0.01)$ for both variables. 
Table 3. Weaning outcomes from Nelore (Bos indicus) beef cows according to temperament

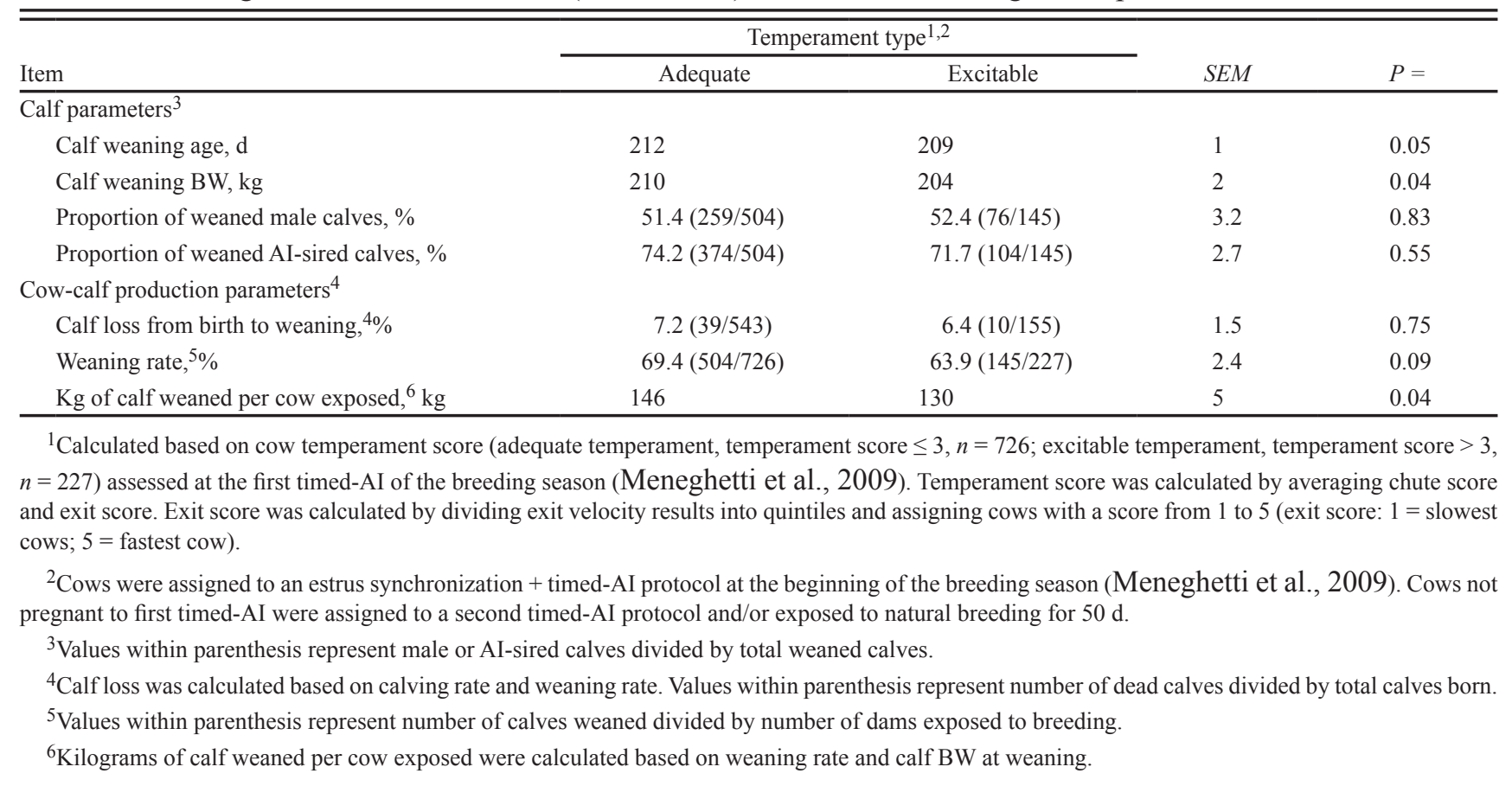

come was detected for serum haptoglobin (linear effect, $P<0.01$; Fig. 1), despite the lack of temperament type effects on this variable. Inflammatory and acute-phase protein responses are known to impair cattle reproductive function by disturbing follicle development, ovulation, and pregnancy establishment (Battaglia et al., 2000; Williams et al., 2001; Hansen et al., 2004). Conversely, hair cortisol concentration was not associated $(P \geq 0.21)$ with pregnancy probability to first timed-AI (data not shown), suggesting that adrenocortical activity prior to and during the estrus synchronization protocol may not impact cow reproductive efficiency to fixed-time AI.

No differences were detected $(P=0.23)$ for pregnancy rates to second timed-AI, natural breeding, and final pregnancy rates (Table 2). The reason for inconsistent results among first timed-AI and subsequent breeding procedures are unknown and cannot be properly addressed herein, particularly because cattle temperament and serum cortisol concentrations were not assessed during these latter events. However, calving rate was less $(P=0.04)$ in EXC vs. ADQ cows (Table 2), which can be attributed to the greater $(P=0.05)$ pregnancy loss detected in EXC vs. ADQ cows (Table 2). Although heightened adrenocortical stress reaction during handling is also expected to impair pregnancy maintenance in cattle with excitable temperament (Merrill et al., 2007; Cooke, 2014), the pregnancy losses observed herein occurred after the end of the breeding season when cattle were seldom handled. Hence, additional mechanisms associating temperament and reproduction in beef females warrant further investigation, including post-conception effects, pregnancy development and maintenance, as well as potential genetic and innate deficiencies within the reproductive system of excitable cows (Cooke, 2014). Accordingly, several genes that may be responsible for cattle temperament have been identified (Schmutz et al., 2001), whereas genetic correlations between temperament and reproductive traits were already reported in Nelore cattle (Barrozo et al., 2012).

No temperament type effects were detected $(P=0.75)$ for calf loss from birth to weaning. Hence, weaning rate tended to be less $(P=0.09)$ in EXC vs. ADQ cows (Table 3), corroborating with results from B. taurus cows (Cooke et al., 2012). Weaning BW was greater $(P=0.04)$ in calves from ADQ cows compared with cohorts from EXC cows (Table 3), which can be directly attributed to a similar temperament type effect $(P=$ 0.05 ) detected for calf weaning age (Table 3 ). The greater weaning age of calves from ADQ cows can be related to temperament type effects detected for first timed-AI and numerical increase in pregnancy rates to second-time $\mathrm{AI}$ in ADQ vs. EXC cows (Table 2), which resulted in ADQ cows calving earlier in the breeding season compared with EXC cows (temperament $\times$ type interaction, $P=0.02$; Fig. 2). Conversely, differences in calf weaning BW should not be associated with proportion of male or proportion of AI-sired calves (Marques et al., 2016), as these variables were similar $(P \geq 0.55)$ between EXC and ADQ cows (Table 3 ). Accordingly, calf weaning BW was similar $(P=0.22)$ between ADQ and EXC when calf weaning age was included as independent covariate (209 vs. $206 \mathrm{~kg}$, respectively; SEM = 2), but was still greater $(P \leq 0.05)$ in ADQ when proportion of male calves weaned (210 vs. $204 \mathrm{~kg}$, respectively; SEM = 2) or AI- 


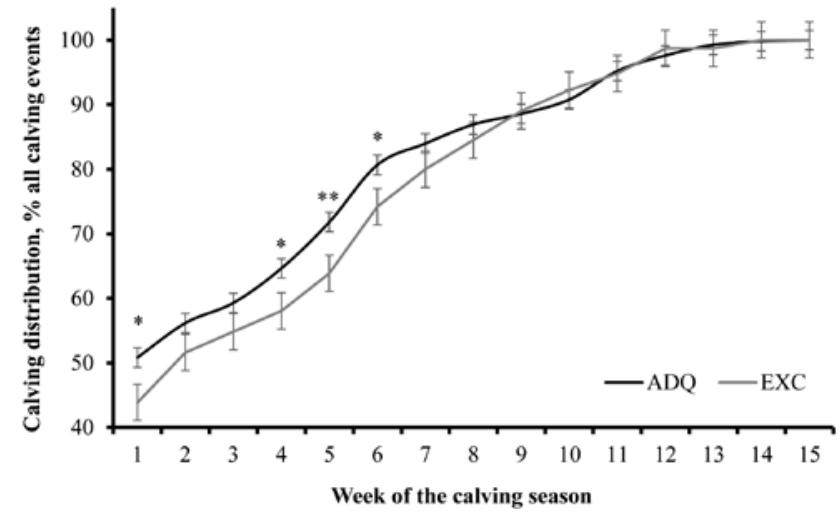

Figure 2. Calving distribution during a 15 -wk calving season in Nelore (Bos indicus) beef cows classified with excitable (EXC) or adequate (ADQ) temperament (Cooke, 2014) at the beginning of the previous breeding season. A temperament type $\times$ week interaction was detected $(P=$ 0.02). Temperament type comparison within week: $* * P=0.01,{ }^{*} P \leq 0.05$.

sired calves weaned (210 vs. $205 \mathrm{~kg}$, respectively; SEM = 2) were included. Lastly, $\mathrm{kg}$ of calf weaned/cow exposed to breeding was less $(P=0.04)$ in EXC vs. ADQ cows (Table 3), agreeing with results from Cooke et al. (2012) in B. taurus females. However, Cooke et al. (2012) did not report temperament type effects on calf weaning BW, likely due to the similar weaning age in calves born from B. taurus classified as excitable or adequate temperament.

Collectively, this experiment provides novel information regarding the negative impacts of excitable temperament on reproductive efficiency and overall productivity in $B$. indicus beef females. More specifically, EXC cows experienced reduced pregnancy rates to first timed-AI, increased pregnancy loss, which resulted in decreased calving and weaning rates compared with cows with ADQ cohorts. Moreover, EXC calved later during the calving season, weaned younger and lighter offspring, which resulted in a $16-\mathrm{kg}$ decrease in $\mathrm{kg}$ of calf weaned/cow exposed to breeding compared with ADQ cows. The exact biological reason for these outcomes are unknown and warrant investigation, given that serum cortisol results can only help explaining temperament type effects on pregnancy rates to first timed-AI. These include, but are not limited to, physiological and genetic relationships between excitable temperament and reproductive function. Nevertheless, this experiment demonstrated that cattle temperament has direct implications on overall production efficiency in cow-calf system based on $B$. indicus females.

\section{LITERATURE CITED}

Araujo, D. B., R. F. Cooke, G. R. Hansen, C. R. Staples, and J. D. Arthington. 2010. Effects of rumen-protected polyunsaturated fatty acid supplementation on performance and physiological responses of growing cattle following transportation and feedlot entry. J. Anim. Sci. 87:4125-4132.
Arthington, J. D., X. Qiu, R. F. Cooke, J. M. B. Vendramini, D. B. Araujo, C. C. Chase, Jr., and S. W. Coleman. 2008. Effects of pre-shipping management on measures of stress and performance of beef steers during a feedlot receiving period. J. Anim. Sci. 86:2016-2023. doi:10.2527/jas.2008-0968

Barrozo, D., M. E. Buzanskas, J. A. Oliveira, D. P. Munari, H. H. R. Neves, and S. A. Queiroz. 2012. Genetic parameters and environmental effects on temperament score and reproductive traits of Nellore cattle. Animal 6:36-40. doi:10.1017/S1751731111001169

Battaglia, D. F., H. B. Krasa, V. Padmanabhan, C. Viguie, and F. J. Karsch. 2000. Endocrine alterations that underlie endotoxininduced disruption of the follicular phase in ewes. Biol. Reprod. 62:45-53. doi:10.1095/biolreprod62.1.45

Burdick, N. C., R. D. Randel, J. A. Carroll, and T. H. Welsh. 2011. Interactions between temperament, stress, and immune function in cattle. Int. J. Zool. 2011:1-9. doi:10.1155/2011/373197

Burnett, T. A., A. M. L. Madureira, B. F. Silper, A. Nadalin, A. M. Tahmasbi, D. M. Veira, and R. L. A. Cerri. 2014. Short communication: Factors affecting hair cortisol concentration in lactating dairy cows. J. Dairy Sci. 97:7685-7690. doi:10.3168/jds.2014-8444

Carroll, J. A., and N. E. Forsberg. 2007. Influence of stress and nutrition on cattle immunity. Vet. Clin. Food. Anim.23:105-149.

Chenoweth, P. J., and L. Ball. 1980. Breeding soundness examination of bulls. In: D. A. Morrow, editor, Current Therapy in Theriogenology. W. B. Saunders Co., Philadelphia, PA. p. 330-339.

Cooke, R. F., and D. W. Bohnert. 2011. Bovine acute-phase response following corticotrophin-release hormone challenge. J. Anim. Sci. 89:252-257. doi:10.2527/jas.2010-3131

Cooke, R. F. 2014. Temperament and acclimation to human handling influence growth, health, and reproductive responses in Bos taurus and B. indicus cattle. J. Anim. Sci. 92:5325:5333. doi:10.2527/jas.2014-8017

Cooke, R. F., and J. D. Arthington. 2013. Concentrations of haptoglobin in bovine plasma determined by ELISA or a colorimetric method based on peroxidase activity. J. Anim. Physiol. Anim. Nutr. 97:531-536. doi:10.1111/j.1439-0396.2012.01298.x

Cooke, R. F., D. W. Bohnert, B. I. Cappellozza, C. J. Mueller, and T. DelCurto. 2012. Effects of temperament and acclimation to handling on reproductive performance of Bos taurus beef females. J. Anim. Sci. 90:3547-3555. doi:10.2527/jas.2011-4768

Cooke, R. F., D. W. Bohnert, M. Meneghetti, T. C. Losi, and J. L. M. Vasconcelos. 2011. Effects of temperament on pregnancy rates to fixed-timed AI in Bos indicus beef cows. Livest. Sci. 142:108-113. doi:10.1016/j.livsci.2011.06.024

Cooke, R. F., J. D. Arthington, D. B. Araujo, and G. C. Lamb. 2009. Effects of acclimation to human interaction on performance, temperament, physiological responses, and pregnancy rates of Brahman-crossbred cows. J. Anim. Sci. 87:4125-4132. doi:10.2527/jas.2009-2021

Curley, K. O., Jr., J. C. Paschal, T. H. Welsh, Jr., and R. D. Randel. 2006. Technical note: Exit velocity as a measure of cattle temperament is repeatable and associated with serum concentration of cortisol in Brahman bulls. J. Anim. Sci. 84:3100-3103. doi: $10.2527 /$ jas.2006-055

da Rosa, G. O., and W. C. Wagner. 1981. Adrenal-gonad interactions in cattle. Corpus luteum function in intact and adrenalectomized heifers. J. Anim. Sci. 52:1098-1105. doi:10.2527/jas1981.5251098x

Dobson, H., A. Y. Ribadu, K. M. Noble, J. E. Tebble, and W. R. Ward. 2000. Ultrasonography and hormone profiles of adrenocorticotrophic hormone (ACTH)-induced persistent ovarian follicles (cysts) in cattle. J. Reprod. Fertil. 120:405-410. doi:10.1530/reprod/120.2.405 
Dobson, H., J. E. Tebble, R. F. Smith, and W. R. Ward. 2001. Is stress really all that important? Theriogenology 55:65-73. doi:10.1016/S0093-691X(00)00446-5

FASS. 2010. Guide for the Care and Use of Agricultural Animals in Agricultural Research and Teaching. 3rd ed. Federation of Animal Science Societies, Savoy, IL.

Fell, L. R., I. G. Colditz, K. H. Walker, and D. L. Watson. 1999. Associations between temperament, performance and immune function in cattle entering a commercial feedlot. Aust. J. Exp. Agric. 39:795-802. doi:10.1071/EA99027

Fordyce, G. E., R. M. Dodt, and J. R. Wythes. 1988. Cattle temperaments in extensive beef herds in northern Queensland. 1. Factors affecting temperament. Aust. J. Exp. Agric. 28:683-687. doi:10.1071/EA9880683

Francisco, C. L., F. D. Resende, J. M. B. Benatti, A. M. Castilhos, R. F. Cooke, and A. M. Jorge. 2015. Impacts of temperament on Nellore cattle: Physiological responses, performance, and carcass characteristics. J. Anim. Sci. 93:5419-5429. doi:10.2527/jas.2015-9411

González-de-la-Vara, M. R., R. A. Valdez, V. Lemus-Ramirez, J. C. Vazquez-Chagoyan, A. Villa-Godoy, and M. C. Romano. 2011. Effects of adrenocorticotropic hormone challenge and age on hair cortisol concentrations in dairy cattle. Can. J. Vet. Res. 75:216-221.

Hansen, P. J., P. Soto, and R. P. Natzke. 2004. Mastitis and fertility in cattle- possible involvement of inflammation or immune activation in embryonic mortality. Am. J. Reprod. Immunol. 51:294 301. doi:10.1111/j.1600-0897.2004.00160.x

Hearnshaw, H., and C. A. Morris. 1984. Genetic and environmental effects on a temperament score in beef cattle. Aust. J. Agric. Res. 35:723-733. doi:10.1071/AR9840723

Hein, K. G., and R. D. Allrich. 1992. Influence of exogenous adrenocorticotropic hormone on estrous behavior in cattle. J. Anim. Sci. 70:243-247. doi:10.2527/1992.701243x

Li, P. S., and W. C. Wagner. 1983. In: vivo and in vitro studies on the effect of adrenocorticotropic hormone or cortisol on the pituitary response to gonadotropin releasing hormone. Biol. Reprod. 29:25-37. doi:10.1095/biolreprod29.1.25

Marques, R. S., R. F. Cooke, M. C. Rodrigues, B. I. Cappellozza, C. K. Larson, P. Moriel, and D. W. Bohnert. 2016. Effects of organic or inorganic $\mathrm{Co}, \mathrm{Cu}, \mathrm{Mn}$, and $\mathrm{Zn}$ supplementation to late-gestating beef cows on productive and physiological responses of the offspring. J. Anim. Sci. 94:1215-1226. doi:10.2527/jas.2015-0036

Marti, S., M. Devant, S. Amatayakul-Chantler, J. A. Jackson, E. Lopez, E. D. Janzen, and K. S. Schwartzkopf-Genswein. 2015. Effect of anti-gonadotropin-releasing factor vaccine and band castration on indicators of welfare in beef cattle. J. Anim. Sci. 93:1581-1591. doi:10.2527/jas.2014-8346
Matsunaga, M. E., J. A. Silva, L. M. Toledo, M. J. R. Paranhos da Costa, J. P. Eler, and J. B. S. Ferraz. 2002. Genetic analysis of temperament in Nelore cattle. Proc. 7th World Congr. Genet. Appl. Livest. Prod. (Montpelier, France) 14:16.

Meneghetti, M., O. G. Sá Filho, R. F. G. Peres, G. C. Lamb, and J. L. M. Vasconcelos. 2009. Fixed-time artificial insemination with estradiol and progesterone for $B$. indicus cows I: Basis for development of protocols. Theriogenology 72:179-189. doi:10.1016/j.theriogenology.2009.02.010

Merrill, M. L., R. P. Ansotegui, P. D. Burns, M. D. MacNeil, and T. W. Geary. 2007. Effects of flunixin meglumine and transportation on establishment of pregnancy in beef cows. J. Anim. Sci. 85:1547-1554. doi:10.2527/jas.2006-587

Moya, D., K. S. Schwatzkopf-Genswein, and D. M. Veira. 2013. Standarization of a non-invasive methodology to measure cortisol in hair of beef cattle. Livest. Sci. 158:138-144. doi:10.1016/j.livsci.2013.10.007

Moya, D., M. L. He, L. Jin, Y. Wang, G. B. Penner, K. S. SchwartzkopfGenswein, and T. A. McAllister. 2015. Effect of grain type and processing index on growth performance, carcass quality, feeding behavior, and stress response of feedlot steers. J. Anim. Sci. 93:3091-3100. doi:10.2527/jas.2014-8680

Rueda, P. M., A. C. Sant'Anna, T. S. Valente, and M. J. P. da Costa. 2015. Impact of the temperament of Nellore cows on the quality of handling and pregnancy rates in fixed-time artificial insemination. Livest. Sci. 177:189-195. doi:10.1016/j.livsci.2015.04.021

Schmutz, S. M., J. M. Stookey, D. C. Winkelman-Sim, C. S. Waltz, Y. Plante, and F. C. Buchanan. 2001. A QTL study of cattle behavioral traits in embryo transfer families. J. Hered. 92:290-292. doi:10.1093/jhered/92.3.290

Stahringer, R. C., R. D. Randel, and D. A. Neuendorff. 1990. Effects of naloxone and animal temperament on serum luteinizing-hormone and cortisol concentrations in seasonally anestrous Brahman heifers. Theriogenology 34:393-406. doi:10.1016/0093-691X(90)90531-W

Vasconcelos, J. L. M., O. G. de Sá Filho, and R. F. Cooke. 2014. Impacts of reproductive technologies on beef production in South America. Adv. Exp. Med. Biol. 752:161-180. doi:10.1007/978-1-4614-8887-3_8

Wagner, J. J., K. S. Lusby, J. W. Oltjen, J. Rakestraw, R. P. Wettemann, and L. E. Walters. 1988. Carcass composition in mature Hereford cows: Estimation and effect on daily metabolizable energy requirement during winter. J. Anim. Sci. 66:603-612. doi:10.2527/jas $1988.663603 x$

Wagner, W. C., R. E. Strohbehn, and P. A. Harris. 1972. ACTH, corticoids, and luteal function in heifers. J. Anim. Sci. 35:789-793. doi:10.2527/jas1972.354789x

Williams, C. Y., T. G. Harris, D. F. Battaglia, C. Viguie, and F. J. Karsch. 2001. Endotoxin inhibits pituitary responsiveness to gonadotropin-releasing hormone. Endocrinology 142:1915-1922. 